\title{
Too tempting to resist? Past success at weight control rather than dietary restraint determines exposure- induced disinhibited eating
}

Citation for published version (APA):

Houben, K., Nederkoorn, C., \& Jansen, A. (2012). Too tempting to resist? Past success at weight control rather than dietary restraint determines exposure-induced disinhibited eating. Appetite, 59(2), 550-555. https://doi.org/10.1016/j.appet.2012.07.004

Document status and date:

Published: 01/10/2012

DOI:

10.1016/j.appet.2012.07.004

Document Version:

Publisher's PDF, also known as Version of record

Document license:

Taverne

Please check the document version of this publication:

- A submitted manuscript is the version of the article upon submission and before peer-review. There can be important differences between the submitted version and the official published version of record.

People interested in the research are advised to contact the author for the final version of the publication, or visit the DOI to the publisher's website.

- The final author version and the galley proof are versions of the publication after peer review.

- The final published version features the final layout of the paper including the volume, issue and page numbers.

Link to publication

\footnotetext{
General rights rights.

- You may freely distribute the URL identifying the publication in the public portal. please follow below link for the End User Agreement:

www.umlib.nl/taverne-license

Take down policy

If you believe that this document breaches copyright please contact us at:

repository@maastrichtuniversity.nl

providing details and we will investigate your claim.
}

Copyright and moral rights for the publications made accessible in the public portal are retained by the authors and/or other copyright owners and it is a condition of accessing publications that users recognise and abide by the legal requirements associated with these

- Users may download and print one copy of any publication from the public portal for the purpose of private study or research.

- You may not further distribute the material or use it for any profit-making activity or commercial gain

If the publication is distributed under the terms of Article 25fa of the Dutch Copyright Act, indicated by the "Taverne" license above, 
Research report

\title{
Too tempting to resist? Past success at weight control rather than dietary restraint determines exposure-induced disinhibited eating
}

\author{
Katrijn Houben*, Chantal Nederkoorn, Anita Jansen \\ Clinical Psychological Science, Maastricht University, P.O. Box 616, 6200 MD Maastricht, The Netherlands
}

\section{A R T I C L E I N F O}

\section{Article history}

Received 1 October 2011

Received in revised form 3 July 2012

Accepted 4 July 2012

Available online 14 July 2012

\section{Keywords:}

Dieting

Self-regulation

Exposure

Inhibitory control

Stop-Signal Task

\begin{abstract}
A B S T R A C T
As the prevalence of obesity is increasing, many people resort to dieting to achieve a healthy body weight. Such dietary restraint has been suggested to cause counterproductive effects leading to disinhibited eating. However, it is more likely that dietary restraint is a by-product of previous difficulties in weight control and disinhibited eating. If so, disinhibition should be related more strongly to unsuccessful weight control than dietary restraint. This possibility was examined in the present study. Participants were exposed to palatable food or to neutral objects. Before and after exposure, we measured craving, general inhibitory control and inhibition of food-related responses with the Stop-Signal Task (SST), and food consumption during a taste test. Results showed that exposure increased craving in both successful and unsuccessful weight regulators. People who were successful at controlling their weight, however, were better able to regulate this temptation compared to unsuccessful weight regulators: while exposure to palatable food reduced inhibitory control over food-related responses and increased food consumption in unsuccessful weight regulators, successful weight regulators did not show such disinhibition. Dietary restraint did not influence any of these findings. Further, the exposure-induced difference in inhibition between successful and unsuccessful weight regulators was specific for food-related responses, as regulatory success did not influence general inhibitory control. Thus, while successful and unsuccessful weight regulators seem equally tempted by palatable food, those who are successful in controlling their weight seem better able to resist these temptations by exerting inhibitory control over appetitive responses toward palatable food.
\end{abstract}

(c) 2012 Elsevier Ltd. All rights reserved.

\section{Introduction}

As overweight and obesity is constantly increasing worldwide, many people resort to different dieting strategies. Maintaining a healthy weight and reducing one's body weight over an extended period of time, however, seems difficult for most people (e.g., Jeffery et al., 2000; Mann et al., 2007; Wing \& Phelan, 2005). Further, many dieters who chronically try to restrict their food intake are characterized by frequent lapses of restraint especially when exposed to palatable food cues (e.g., Fedoroff, Polivy, \& Herman, 1997; Herman \& Polivy, 1980; Jansen \& Van den Hout, 1991), stronger positive attitudes toward palatable food (e.g., Houben, Roefs, \& Jansen, 2010), and increased disinhibition (Nederkoorn, Van Eijs, \& Jansen, 2004). Research findings such as these contributed to the belief that attempting to control one's food intake and body weight has counterproductive effects and causes a pattern of disinhibited overeating.

In contrast to this idea, dietary restraint in fact generally seems to be related to less overeating and reduced weight in the long-

\footnotetext{
* Corresponding author.

E-mail address: K.Houben@maastrichtuniversity.nl (K. Houben).
}

term rather than increased overeating and weight gain (Johnson, Pratt, \& Wardle, 2012). Therefore, it is probably more likely that disinhibited eating causes increased dietary restraint rather than vice versa (Jansen et al., 2003; Johnson et al., 2012; Lowe, 1993; Lowe \& Levine, 2005). Specifically, people who experienced difficulty controlling their food intake in the past, are probably more likely to attempt to restrict their food intake in order to attain a reduction in body weight. In this case, dietary restraint should be merely a by-product of unsuccessful weight control and overeating rather than a causal factor leading to disinhibited eating. So what distinguishes people who are successful at controlling their weight from those who are unsuccessful in attaining and maintaining a healthy body weight? One of the key differences between successful and unsuccessful weight regulation probably involves self-control. Self-control (or inhibitory control) refers to the ability to inhibit a behavioral impulse in order to attain higher-order goals, such as weight loss and maintenance. Indeed, research has demonstrated that increased inhibitory control predicts increased weight loss during treatment (Nederkoorn, Braet, Van Eijs, Tanghe, \& Jansen, 2006). As such, self-control may be intimately connected to successful weight control so that successful weight regulators are better able to control themselves 
in tempting situations where unsuccessful weight regulators are prone to indulge.

In line with this idea, research has demonstrated that tempting, palatable food activates positive affect to the same extent in successful and unsuccessful weight regulators (e.g., Van Koningsbruggen, Stroebe, \& Aarts, 2011). Hence, people who can successfully maintain a healthy body weight appear to be no less tempted by palatable food cues compared to unsuccessful weight regulators. However, in contrast to unsuccessful weight regulators, people who are successful at controlling their weight may be better able to regulate such positive, appetitive responses to palatable food cues. Indirect evidence for this idea comes from studies that have demonstrated that food intake is more easily regulated in line with dieting intentions when self-control resources are high. In contrast, when self-control resources are low, eating behavior is more strongly guided by appetitive reactions to palatable food such as positive affect (e.g., Hofmann \& Friese, 2008; Hofmann, Rauch, \& Gawronski, 2007). Further, successful weight regulators have been found to activate a dieting goal in response to palatable food cues, while unsuccessful weight regulators seem to inhibit such dieting goals (e.g.,Fishbach, Friedman, \& Kruglanski 2003; Papies, Stroebe, \& Aarts, 2008; Stroebe, Mensink, Aarts, Schut, \& Kruglanski, 2008; Van Koningsbruggen, Stroebe, \& Aarts, 2011). According to Fishbach and coworkers (2003), such facilitative links between palatable food cues and the higher-order goal of dieting develop when people are repeatedly and successfully able to exert self-control in tempting situations.

Together, these findings suggest that successful weight regulators are better able to inhibit appetitive responses to palatable food cues in situations where unsuccessful weight regulators exhibit disinhibition. Further, if dietary restraint is indeed merely a byproduct of unsuccessful weight control, this relationship between inhibitory control and successful weight control should be uninfluenced by dietary restraint status. The aim of the present study was to test this hypothesis. Here, successful and unsuccessful weight regulators were either exposed to palatable food or to neutral objects. It was expected that such exposure to tempting, palatable food would reduce inhibitory control in unsuccessful weight regulators, but not in successful weight controllers, indicating that unsuccessful weight regulators are less able to regulate their behavior in tempting situations. Moreover, since the problem of disinhibited eating specifically pertains to the food domain, we also examined whether exposure to palatable food decreases general inhibitory control, or more specifically inhibitory control over food-related responses, in unsuccessful compared to successful weight regulators. Finally, we expected an increase in food consumption following exposure to palatable food in unsuccessful weight regulators but not in successful weight regulators.

\section{Method}

\section{Participants}

Fifty-three female participants completed the study. Inspection of the data, however, revealed two influential outliers (Leverage $>3(\mathrm{k}+1) / n)$ and one participant did not follow the instructions during the computer task. These participants were therefore excluded, and the final sample consisted of 50 participants (age: $M=21.54, S D=3.18$; Body Mass Index $\left(B M I: k g / \mathrm{m}^{2}\right): M=22.52$, $S D=2.81)$. Participants were randomly assigned to one of two conditions: Exposure $(n=26)$ or control $(n=24)$. The two conditions did not differ significantly in age or BMI (both $F<1$ ). The study was approved by the Ethics Committee of the Faculty of Psychology and Neuroscience, Maastricht University.

\section{Materials and measures}

Exposure to food vs. control

During the food exposure (cf. Nederkoorn et al., 2004), three large bowls of food were presented to participants. One bowl contained two kinds of crisps (natural flavor and paprika flavor), the second bowl contained two kinds of party nuts (paprika flavor and bacon-cheese flavor), and the third bowl contained two kinds of chocolate (dark chocolate and milk chocolate). First, participants were asked to look at the first bowl of food. They were then instructed to imagine how the food would taste. Next, they were asked to smell the food thoroughly and then they tasted a small piece of the food. The same procedure was then repeated with the second and third bowl of food. In total, the food exposure lasted $10 \mathrm{~min}$. At the end of the exposure, the bowls of food were placed besides the computer and participants were told that they would be free to eat as much of the food as they wanted at the end of the experiment. In the control condition, participants performed a similar exposure, but now the bowls of food were replaced with bowls containing neutral objects (tree bark, bath salts, and bath pearls). Participants were instructed to look at the bowls, to imagine using these objects, and to smell the objects. The neutral exposure also lasted $10 \mathrm{~min}$. At the end of the exposure, the three bowls were placed beside the computer screen.

\section{Stop-Signal Task (SST)}

The SST (Logan, Schachar, \& Tannock, 1997) was used to measure inhibitory control. The SST involves two concurrent tasks: A go task, which is a choice reaction time task, and a stop task, which involves a stop signal that requires participants to inhibit their responses to the go task. Here, we used two variants of the SST: One to measure general response inhibition ability, and another to measure response inhibition specifically for food. During the general SST, the letter $\mathrm{O}$ or the letter X was presented for $1000 \mathrm{~ms}$, preceded by a 500 ms fixation point. During go trials, participants had to respond as fast as possible to the $\mathrm{X}$ and the $\mathrm{O}$ using a left and $\mathrm{a}$ right response key on the keyboard (e.g., press left for $\mathrm{X}$ and press right for $\mathrm{O}$; instructions were counterbalanced across participants). During the food-specific SST, four pictures of food (crisps, chocolate, party nuts, and chocolate chip cookies) were presented for $1000 \mathrm{~ms}$, either in landscape format or in portrait format. During go trials, participants had to respond as fast as possible to these pictures using a left and a right response key on the keyboard (e.g., press left for portrait and press right for landscape; instructions were counterbalanced across participants).

In both the general SST, and the food-specific SST, an auditory stop signal was presented (through headphones) on $25 \%$ of the trails. Participants were instructed not to respond when this stop signal was presented. Both SST variants consisted of two practice blocks without stop signals, one practice block with stop signals, and two test blocks of 64 trials. In the test blocks, the delay between the go signal ( $\mathrm{X}$ or $\mathrm{O}$ for the general SST; food pictures for the food-specific SST) and the stop signal was initially set at $250 \mathrm{~ms}$. Depending on the performance of the participants, a tracking procedure adapted the stop-signal delay dynamically: If participants succeeded in inhibiting their response, the stop-signal delay was increased by $50 \mathrm{~ms}$, thereby making it more difficult to inhibit the next trial. If participants failed to inhibit their response, stopsignal delay was decreased by $50 \mathrm{~ms}$, thereby making it easier to inhibit the next trial. The SST was designed to enable participants to correctly inhibit $50 \%$ of the stop trials.

The assumption underlying this task is that response inhibition succeeds or fails depending on the relative finishing time of two parallel processes that race against each other: a go process triggered by the go signal, and a stop process triggered by the stop signal. If the stop process finishes before the go process, subjects 
inhibit their response. However, if the go process finishes before the stop process, subjects fail to inhibit their response. The tracking procedure is designed to find a stop-signal delay at which point the go process and the stop process on average finish at the same time. The two variables of interest are: (1) the go signal reaction time, and (2) the stop-signal delay, which represents the starting point of the stop process. From these two variables, it is possible to estimate the covert latency of the stop process, the stop signal reaction time (SSRT), by subtracting the stop delay from go RT. SSRT thus reflects the time required for successful inhibition of the go response, and therefore higher SSRTs indicate decreased inhibitory control.

\section{Taste test}

During the taste test, the consumption of three types of palatable food (the same as used during the food exposure) was measured. Participants were asked to taste and rate the three types of food that were placed in front of them in large bowls. Participants were instructed to consume as much or as little as they wished to judge the taste of the food products. They evaluated the three types of food on several dimensions, including palatability of the food, smell, and texture, on different $100 \mathrm{~mm}$ Visual Analogue Scales (VAS). The experimenter left the test room during the taste test and returned after $10 \mathrm{~min}$ and removed the bowls of food. The primary variable of interest was not how participants rated the types of food, but rather how much they consumed of each type of food. Without the participants' knowledge, the experimenter weighed the bowls of food before and after the taste test outside the test room. Energy intake was calculated for each food product by multiplying weight consumed of each food product by its caloric density.

\section{Perceived self-regulatory success (PSRS)}

Participants' perceived self-regulatory success in attaining and maintaining a healthy weight was assessed with the three-item scale developed by Fishbach et al. (2003). On a 7-point Likert scale, participants rated the extent to which they were successful in watching their weight, they were successful in losing weight, and they found it difficult to stay in shape (this last item was reversed coded). Internal consistency has previously been reported to range between $\alpha=.60-.80$ (Fishbach et al., 2003; Meule, Papies, \& Kübler, 2012; Van Koningsbruggen, Stroebe, \& Aarts, 2011; Van Koningsbruggen, Stroebe, Papies, \& Aarts, 2011; Present study: $\alpha=.61$ ).

\section{Dietary restraint}

Dietary restraint was measured using the revised Restraint Scale (RS; Herman \& Polivy, 1980). The RS is a self-report questionnaire consisting of 10 items assessing concern for dieting and weight fluctuations. The maximum score on this scale is 35 , while the minimum score is 0 . Higher scores indicate an increased intention to restrict food intake.

\section{Craving for food}

Participants rated how much they craved to eat something at that specific moment on a $100 \mathrm{~mm}$ VAS (no craving at all - a lot of craving).

\section{Hunger}

Participants rated their hunger at that specific moment on a $100 \mathrm{~mm}$ VAS (not at all hungry - very hungry).

\section{Procedure}

Participants were recruited via advertisements in the university building. Participants were asked not to eat anything for $2 \mathrm{~h}$ before the start of the study. As cover story, participants were told that this study was about attention for food and they were informed that they would perform a number of computer tasks, fill out questionnaires pertaining to food, and taste and rate food products. After giving consent, participants performed the general SST and the food SST, in this order. Next, participants rated their craving for food and hunger, and they were subsequently subjected to the food exposure or the control exposure. Following exposure, participants again rated their craving and hunger. Next, participants performed the general SST and the food SST for a second time and they performed the taste test. Finally, participants filled out the PSRS and the RS, and weight and length were measured to calculate BMI. At the end of the study, all participants were thanked for their cooperation and received course credit or a gift certificate as remuneration for their participation.

\section{Results}

\section{Statistical analyses}

First, we examined correlations between the PSRS, RS and BMI to check whether successful weight control is indeed associated with lower BMI and less weight fluctuations compared to dietary restraint. Next, we examined the effect of exposure versus control on craving, inhibitory control, and consumption ${ }^{1}$ using Univariate analyses of Covariance (ANCOVA) with condition (exposure vs. control) as a between-subjects factor. Self-regulatory success and dietary restraint were added to the model as continuous covariates instead of performing a median split to minimize loss of power (van Breukelen \& van Dijk, 2007) ${ }^{2}$. Means for unsuccessful and successful weight regulators, and for high versus low restrained eaters are estimated at respectively $1 S D$ above and $1 S D$ below the mean score. To control for individual differences on the dependent variables at baseline, baseline scores were always entered as a covariate as well as hunger ratings (averaged over the two times of assessment). Partial eta squared $\left(\eta_{\mathrm{p}}{ }^{2}\right)$ is reported as a measure of effect size.

\section{BMI, dietary restraint and successful weight control}

People who perceived themselves as more successful in controlling their body weight had a lower BMI, $r=-.40, p=.01$, while increased dietary restraint was related to a higher BMI, $r=.33$, $p=.02$. Further, we calculated difference scores between participants' current weight and their ideal weight (current - ideal) and between participants' current weight and their maximum weight (maximum - current). While successful weight control was associated with smaller differences between one's current weight and ideal weight, $r=-.31, p=.03$, dietary restraint was related to higher discrepancies between one's current weight and ideal weight, $r=.43, p<.01$. Results showed a similar pattern with respect to correlations of successful weight control and dietary restraint with current versus maximum weight differences scores, but these correlations were not significant, $r=-.26, p=.08$ and $r=.23, p=.11$, respectively. The correlation between successful weight control and dietary restraint was not statistically significant, $r=-.23$, $p=.11$.

\footnotetext{
1 Total food consumption was calculated as the total energy intake summed across the three food products. This dependent variable was then log-transformed in order to achieve a normal distribution for the dependent variable.

2 The interaction between dietary restraint and weight control success as well as the three-way interaction coefficient were initially also included in all analyses. Inclusion of these interaction terms revealed the same pattern of results, while none of these interactions reached significance. To preserve power, these interaction terms were then excluded, and results are reported for the analyses without these interaction terms.
} 


\section{Craving}

As a manipulation check, we examined whether the food exposure increased craving for food as intended. In addition to a significant effect of baseline craving, $F(1,42)=24.49, p<.001, \eta_{\mathrm{p}}{ }^{2}=.37$, and hunger, $F(1,42)=4.59, p=.04, \eta_{\mathrm{p}}{ }^{2}=.10$, results showed a significant effect of condition, $F(1,42)=29.89, p<.001, \eta_{\mathrm{p}}{ }^{2}=.42$, indicating that craving for food was significantly higher following the food exposure $(E M M=73.27, S E=2.75)$ than following the control exposure to neutral objects $(E M M=51.84, S E=2.84)$. Neither the main effects of self-regulatory success, $F(1,42)=1.31, p=.26$, $\eta_{\mathrm{p}}{ }^{2}=.03$, and dietary restraint, $F(1,42)=1.15, p=.29, \eta_{\mathrm{p}}{ }^{2}=.03$, nor their interaction effects were significant: Condition $\times$ success, $F(1,42)=.49, \quad p=.49, \quad \eta_{\mathrm{p}}{ }^{2}=.01 ; \quad$ Condition $\times$ restraint, $\quad F(1$, $42)=.62, p=.44, \eta_{\mathrm{p}}^{2}=.01$.

\section{Inhibitory control}

With respect to the general SST, results only showed a significant effect of baseline SSRT, $F(1,42)=24.86, p<.001, \eta_{\mathrm{p}}{ }^{2}=.38$, while none of the other effects reached significance: Condition, $F(1,42)=.04, p=.85, \eta_{\mathrm{p}}^{2}<.01$; Success, $F(1,42)=.51, p=.48$, $\eta_{\mathrm{p}}{ }^{2}=.01 ;$ Dietary restraint, $F(1,42)=2.72, p=.11, \eta_{\mathrm{p}}{ }^{2}=.06$; Condition $\times$ success, $F(1,42)=.23, p=.63, \eta_{\mathrm{p}}{ }^{2}=.01$; Condition $\times$ restraint, $F(1,42)=.76, p=.39, \eta_{\mathrm{p}}^{2}=.02$. As demonstrated in Fig. 1, there were no significant differences in general response inhibition between the food exposure condition and the control condition for participants who were successful at weight control, nor for participants who were unsuccessful at controlling their weight.

In contrast, results for the food-specific SST showed a marginally significant interaction effect between condition and dieting success, $F(1,42)=3.16, p=.08, \eta_{\mathrm{p}}{ }^{2}=.07$, in addition to a significant effect of baseline food-specific SSRT, $F(1,42)=21.39, p<.001$, $\eta_{\mathrm{p}}{ }^{2}=.34$. None of the other effects reached significance: Condition, $F(1,42)=1.47, p=.23, \eta_{\mathrm{p}}^{2}=.03$; Success, $F(1,42)=.05, p=.83$, $\eta_{\mathrm{p}}{ }^{2}<.01$; Dietary restraint, $F(1,42)=.04, p=.85, \eta_{\mathrm{p}}{ }^{2}<.01$; Condition $\times$ restraint, $F(1,42)=.83, p=.37, \eta_{\mathrm{p}}{ }^{2}=.02$. Importantly, post hoc ANOVAs demonstrated that, in unsuccessful weight regulators, food-specific inhibitory control was significantly lower in the food exposure condition compared to the control condition, $F(1$, 42 ) $=4.53, p=.04, \eta_{\mathrm{p}}{ }^{2}=.10$ (see Fig. 2). In successful dieters, in

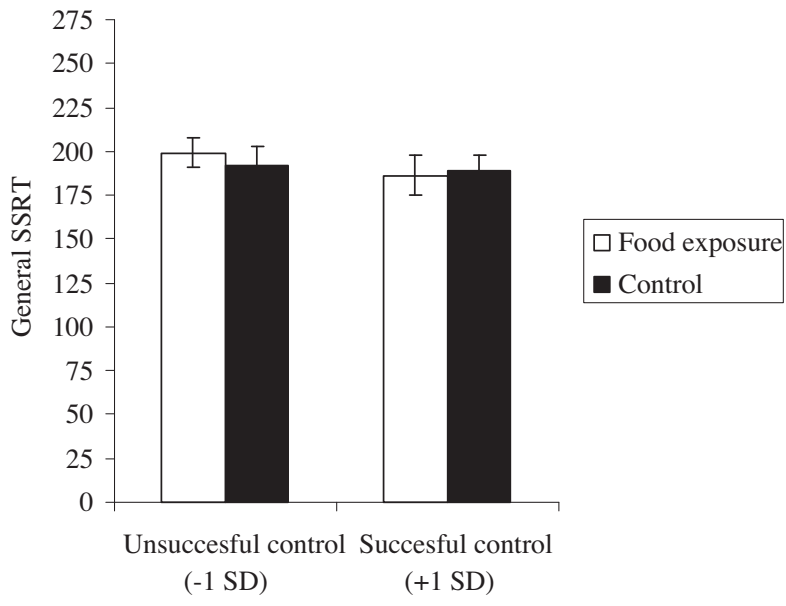

Fig. 1. Estimated marginal means (with standard errors) for general response inhibition (SSRT) following food exposure versus control, separately for successful versus unsuccessful weight regulators (respectively $1 S D$ above or below the mean PSRS score). Higher SSRT scores indicate increased impulsivity or decreased response inhibition.

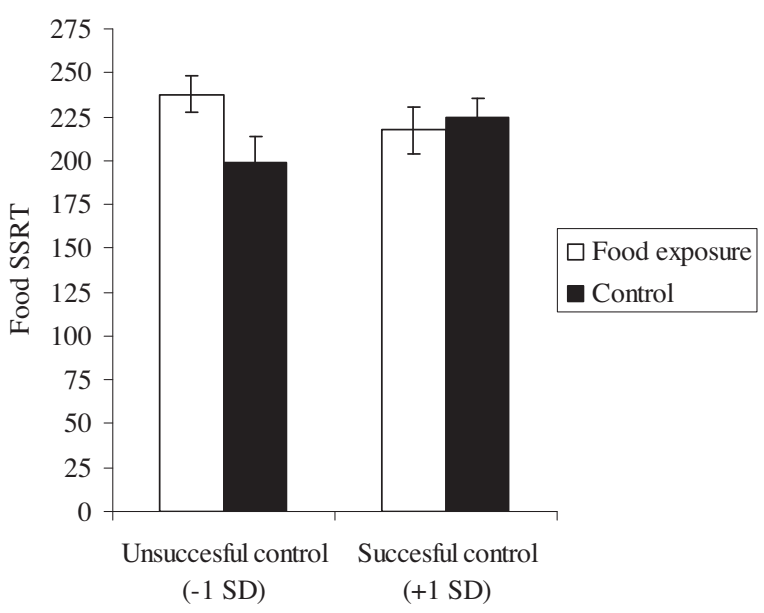

Fig. 2. Estimated marginal means (with standard errors) for food-specific response inhibition (SSRT) following food exposure versus control, separately for successful versus unsuccessful weight regulators (respectively $1 S D$ above or below the mean PSRS score). Higher SSRT scores indicate increased impulsivity or decreased response inhibition.

contrast, results showed no significant difference in food-specific response inhibition between the food exposure condition and the control condition, $F(1,42)=.18, p=.67, \eta_{\mathrm{p}}^{2}<.01$.

\section{Food consumption}

In addition to a significant effect of hunger, $F(1,43)=5.05$, $p=.03, \eta_{\mathrm{p}}{ }^{2}=.11$, the main effect of dietary restraint was also significant, $F(1,43)=6.29, p=.02, \eta_{\mathrm{p}}^{2}=.13$, indicating increased food intake in unrestrained eaters $(E M M=5.32, S E=.12)$ compared to restrained eaters $(E M M=4.87, S E=.13)$. Importantly, the expected interaction between weight control success and condition was also significant, $F(1,43)=4.87, p=.03, \eta_{\mathrm{p}}{ }^{2}=.10$. None of the other effects reached significance: Condition, $F(1,43)=.77, p=.39$, $\eta_{\mathrm{p}}{ }^{2}=.02$; Success, $F(1,43)=.13, p=.72, \eta_{\mathrm{p}}{ }^{2}<.01$; Condition $*$ dietary restraint, $F(1,43)=.21, p=.65, \eta_{\mathrm{p}}{ }^{2}=.01$. Post-hoc ANOVAs demonstrated that unsuccessful weight regulators consumed significantly more calories following the food exposure $(M=228.19$, $S D=31.93)$ compared to the exposure to neutral objects $(M=137.11, S D=44.67), F(1,43)=4.71, p=.04, \eta_{\mathrm{p}}{ }^{2}=.10$ (see Fig. 3). For participants who were successful at controlling their

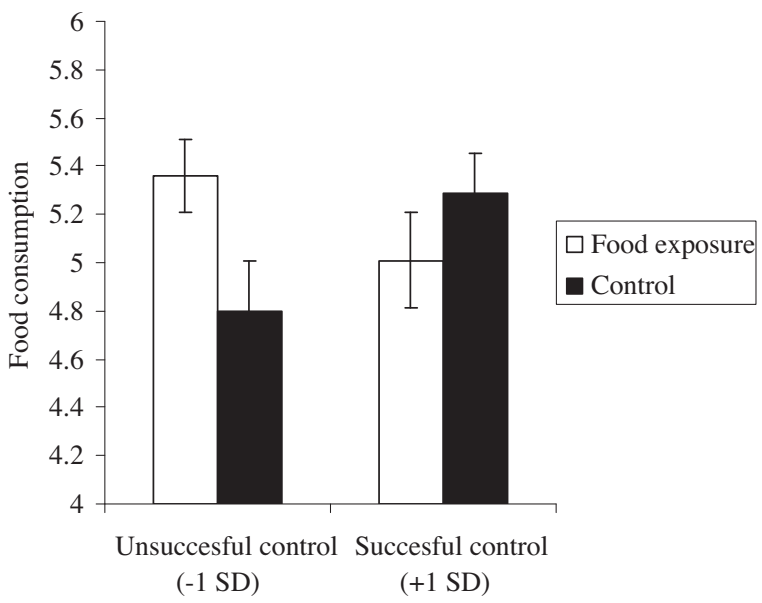

Fig. 3. Estimated marginal means (with standard errors) for food consumption (log transformed amount of calories) during the taste test following food exposure versus control, separately for successful versus unsuccessful weight regulators (respectively $1 S D$ above or below the mean PSRS score) 
weight, in contrast, results showed no significant difference in caloric intake following food exposure $(M=190.70, S D=41.34)$ versus control exposure $(M=254.36, S D=33.67), F(1,43)=1.22$, $p=.28, \eta_{\mathrm{p}}^{2}=.03$.

Thus, exposure to palatable food not only decreased inhibitory control in unsuccessful weight regulators, but also increased their food intake. Inhibitory control and food intake of successful weight regulators, in contrast, were unaffected by exposure to palatable food. Next, we examined whether inhibitory control was related to food intake using regression analysis. Specifically, we regressed caloric intake on general SSRT scores at posttest, food-specific SSRT scores at posttest, and hunger. While the prediction of food intake by hunger, $\beta=.26, p=.07$, and general inhibitory control, $\beta=-.21$, $p=.25$, was not statistically significant, decreased food-specific inhibitory control (i.e., higher SSRT) significantly predicted an increase in food intake, $\beta=.37, p=.04$, suggesting that increased food intake in unsuccessful weight regulators following exposure was caused by lowered food-specific inhibitory control.

\section{Discussion}

The goal of this study was to test the hypothesis that success at controlling one's weight, rather than dietary restraint, is related to disinhibited eating. Specifically, it was expected that people who are unsuccessful at controlling their weight would show decreased inhibitory control and increased food consumption following exposure to tempting food relative to control exposure. No such disinhibition effect was expected in successful weight regulators. Moreover, it was expected that dietary restraint would not influence these effects, indicating that previous success at controlling one's weight is a stronger determinant of disinhibited eating than dietary restraint intentions.

While the exposure to palatable food increased craving to an equal extent in successful and unsuccessful weight regulators, only unsuccessful weight regulators also showed a reduction in their ability to regulate this temptation following exposure. Specifically, inhibitory control over food-related responses was significantly lower in unsuccessful weight regulators who were exposed to palatable food compared to unsuccessful weight regulators in the control condition. Moreover, in a subsequent taste test, people who were unsuccessful at controlling their weight also consumed significantly greater amounts of food following exposure relative to control. In contrast, successful weight regulators did not show evidence for such a disinhibition of food-related responses following exposure, and also did not consume more food relative to successful weight regulators who were not exposed to the food cues. Importantly, the exposure-induced difference in inhibition between successful and unsuccessful weight regulators was specific for food-related responses, as we found no influence of weight control success on general inhibitory control.

Thus, both successful and unsuccessful weight regulators seem equally tempted by palatable food (e.g., Van Koningsbruggen, Stroebe, \& Aarts, 2011; present study), however, only unsuccessful weight controllers also show less inhibitory control after exposure to palatable food. In contrast, inhibitory control in successful weight controllers remains unaffected by exposure to palatable food. Such repeated, successful attempts at self-regulation may then eventually foster facilitative links between palatable food cues and the higher-order dieting goal that further contribute to effective self-control (Fishbach et al., 2003) and may eventually even cause extinction of appetitive responses to palatable food cues (Jansen, Stegerman, Roefs, Nederkoorn, \& Havermans, 2010). Hence, evidence up to now seems to suggest that the difference between successful and unsuccessful weight regulators does not appear to lie in the strength of appetitive responses to palatable foods but rather in the ability to regulate appetitive responses to palatable food cues, i.e., food cue reactivity. It is, however, important to note that research in this area is still scarce and future research should further examine whether successful weight regulation may also be associated with lower appetitive motivation or reward-sensitivity for palatable food.

Importantly, dietary restraint did not influence the effect of exposure on inhibitory control or on food consumption. Hence, the present findings indicate that previous experiences with successful weight control rather than restraint are related to changes in inhibitory control and to consumption following exposure to palatable food cues. While it certainly is true that restraint is related to overeating and disinhibition (e.g., Fedoroff et al., 1997; Herman \& Polivy, 1980; Jansen \& Van den Hout, 1991; Nederkoorn et al., 2004), restraint does not seem to be a causal factor in overeating and is more likely to be a consequence of the tendency to overeat (Jansen et al., 2003; Johnson et al., 2012; Lowe, 1993; Lowe \& Levine, 2005). In line with this idea, the present findings clearly show that a lack of success in controlling one's weight is a more important predictor of disinhibition than restraint: Exposure to food cues decreases inhibitory control in specifically those people who have been unsuccessful at maintaining a healthy weight in the past, leading to disinhibited eating patterns.

A limitation to the present study, however, is that we used the PSRS to measure self-regulatory success in maintaining a healthy weight (Fishbach et al., 2003), which presumes that someone can only remain at a healthy weight (i.e., successful weight regulation) given the engagement of effortful self-control. While this may be true for many people, there are probably also many people who are able to maintain a normal weight without having to exert control to do so. Unfortunately, the PSRS cannot make this distinction between successful, effortless weight management and successful, effortful weight control. Thus, the PSRS probably only measures whether or not someone is able to stay at a healthy weight, regardless of whether self-control needs to be exerted to achieve this goal. In line with this idea, the present findings also do not show an increase in inhibitory control following food exposure in successful weight regulators, indicating that successful weight management is not per se related to increased self-control in tempting situations.

However, what is clear from the present findings is that people who are unsuccessful in staying at a healthy weight show a decrease in inhibitory control in tempting situations (i.e., following exposure to palatable food cues), which subsequently leads to increased food intake. The next question then, is whether inhibitory control can somehow be strengthened to increase dieting success and weight loss in this population. Although inhibitory control abilities show a high heritability, this should not be taken as evidence that these abilities are not amenable to change (Friedman et al., 2008). As a result, more and more research is now being devoted to testing new ways to improve inhibitory control capacity in a wide number of research domains. Recently, it was demonstrated that training inhibition can be effective also in the domain of eating behavior. Specifically, when participants had to consistently withhold their responses to palatable food during a training version of the SST, consumption of that food was significantly reduced during a subsequent taste test (Houben, 2011). Moreover, strengthening inhibitory control proved especially effective for people who already experienced difficulty controlling their food intake. Similarly, recent research showed that implementation intentions as a reminder of dieting was an effective strategy to boost unsuccessful weight regulators' self-control when exposed to tempting food cues while successful weight regulators consumed less, regardless of implementation intentions (Van Koningsbruggen, Stroebe, Papies et al., 2011). Hence, it would be interesting for future research to further examine the value of inhibitory control training in unsuccessful regulators who appear unable to successfully exert 
inhibitory control when tempted by palatable food. As such, inhibitory control training may prevent weight gain and stimulate weight loss by increasing resilience to everyday temptations.

In conclusion, successful weight control depends on the ability to inhibit behavioral responses toward palatable food in order to attain the higher-order goal of attaining a healthy weight. While unsuccessful weight regulators show disinhibition of food-related responses in response to palatable food cues, successful weight regulators do not show such disinhibition effects in tempting situations. Moreover, dietary restraint does not influence this relationship, suggesting that increased dietary restraint is a consequence, rather than a cause of disinhibited eating patterns. Further, unsuccessful weight control appears to be associated with a disinhibition problem specifically tied to the domain of eating. Thus, given that successful weight maintenance is connected to the ability to control oneself in tempting situations, the next step would be to identify the best procedures to enhance self-control in order to support weight loss and maintenance.

\section{References}

Fedoroff, I. C., Polivy, J., \& Herman, C. P. (1997). The effect of pre-exposure to food cues on the eating behaviour of restrained and unrestrained eaters. Appetite, 28, 33-47.

Fishbach, A., Friedman, R. S., \& Kruglanski, A. W. (2003). Leading us not unto temptation. Momentary allurements elicit overriding goal activation. Journal of Personality and Social Psychology, 84, 296-309.

Friedman, N. P., Miyake, A., Young, S. E., DeFries, J. C., Corley, R. P., \& Hewitt, J. K. (2008). Individual differences in executive functions are almost entirely genetic in origin. Journal of Experimental Psychology: General, 137, 201-225.

Herman, C. P., \& Polivy, J. P. (1980). Restrained eating. In A. J. Stunkard (Ed.), Obesity (pp. 208-225). Philadelphia: Saunders.

Hofmann, W., \& Friese, M. (2008). Impulses got the better of me. Alcohol moderates the influence of implicit attitudes toward food cues on eating behavior. Journal of Abnormal Psychology, 117, 420-427.

Hofmann, W., Rauch, W., \& Gawronski, B. (2007). And deplete us not into temptation. Automatic attitudes, dietary restraint, and self-regulatory resources as determinants of eating behavior. Journal of Experimental Social Psychology, 43, 497-504.

Houben, K. (2011). Overcoming the urge to splurge. The role of inhibitory control in eating behavior. Journal of Behavior Therapy and Experimental Psychiatry, 42, 384-388.
Houben, K., Roefs, A., \& Jansen, A. (2010). Guilty pleasures. Implicit preferences for high calorie food in restrained eating. Appetite, 55, 18-24.

Jansen, A., Stegerman, S., Roefs, A., Nederkoorn, C., \& Havermans, R. (2010). Decreased salivation to food cues in formerly obese succesful dieters. Psychotherapy and Psychosomatics, 79, 257-258.

Jansen, A., Theunissen, N., Slechten, K., Nederkoorn, C., Boon, B., Mulkens, S., et al. (2003). Overweight children overeat after exposure to food cues. Eating Behaviors, 4, 197-209.

Jansen, A., \& Van den Hout, M. (1991). On being led into temptation. 'Counterregulation' of dieters after smelling a 'preload'. Addictive Behaviors, 5, 247-253.

Jeffery, R. W., Epstein, L. H., Wilson, G. T., Drewnowski, A., Stunkard, A. J., \& Wing, R. R. (2000). Long-term maintenance of weight loss. Current status. Health Psychology, 19, 5-16.

Johnson, F., Pratt, M., \& Wardle, J. (2012). Dietary restraint and self-regulation in eating behavior. International Journal of Obesity, 36, 665-674.

Logan, G. D., Schachar, R. J., \& Tannock, R. (1997). Impulsivity and inhibitory control. Psychological Science, 8, 60-64.

Lowe, M. R. (1993). The effects of dieting on eating behavior. A three-factor model. Psychological Bulletin, 114, 100-121.

Lowe, M. R., \& Levine, A. S. (2005). Eating motives and the controversy over dieting. Eating less than needed versus less than wanted. Obesity Research, 13, 797-806.

Mann, T., Tomiyama, A. J., Westling, E., Lew, A.-M., Samuels, B., \& Chatman, J. (2007) Medicare's search for effective obesity treatments. Diets are not the answer. American Psychologist, 62, 220-233.

Meule, A., Papies, E. K., \& Kübler, A. (2012). Differentiating between successful and unsuccessful dieters. Validity and reliability of the Perceived Self-Regulatory Success in Dieting Scale. Appetite, 58, 822-826.

Nederkoorn, C., Braet, C., Van Eijs, Y., Tanghe, A., \& Jansen, A. (2006). Why obese children cannot resist food. The role of impulsivity. Eating Behaviors, 7, 315-322.

Nederkoorn, C., Van Eijs, Y., \& Jansen, A. (2004). Restrained eaters act on impulse. Personality and Individual Differences, 37, 1651-1658.

Papies, E. K., Stroebe, W., \& Aarts, H. (2008). Healthy cognition. Processes of selfregulatory success in restrained eating. Personality and Social Psychology Bulletin, $34,1290-1300$.

Stroebe, W., Mensink, W., Aarts, H., Schut, H., \& Kruglanski, A. W. (2008). Why dieters fail. Testing the goal conflict model of eating. Journal of Experimental Social Psychology, 44, 26-36.

van Breukelen, G. J. P., \& van Dijk, K. R. A. (2007). Use of covariates in randomized controlled trials. Journal of International Neuropsychological Society, 13, 903-904.

Van Koningsbruggen, G. M., Stroebe, W., \& Aarts, H. (2011). Through the eyes of dieters. Biased size perception of food following tempting food primes. Journal of Experimental Social Psychology, 47, 293-299.

Van Koningsbruggen, G. M., Stroebe, W., Papies, E. K., \& Aarts, H. (2011). Implementation intentions as goal primes. Boosting self-control in tempting environments. European Journal of Social Psychology, 41, 551-557.

Wing, R. R., \& Phelan, S. (2005). Long-term weight loss maintenance. American Journal of Clinical Nutrition, 82, 222S-225S. 